\title{
Efficiency of wet mechanoactivation of granite using different milling units
}

\author{
Alla Cherevatova ${ }^{1}$, Natalia $_{\text {Kozhukhova }}{ }^{*}$, Irina Zhernovskaya $^{1}$, Mayya Osadchaya $^{1}$, Igor \\ Klepak $^{1}$ and Marina Kozhukhova ${ }^{2}$ \\ ${ }^{1}$ Belgorod State Technological University named after V.G. Shukhov, 46 Kostukova str., 308012, \\ Russia \\ ${ }^{2}$ University of Wisconsin-Milwaukee, WI 53211, Milwaukee, 3200 North Cramer str., USA
}

\begin{abstract}
The opportunity of granite-based aluminosilicate nanostructured binders (NB) with polycondencation-polymerization consolidation mechanism using the different types of milling units. The comparative analysis of mechanoactivation performance of used milling units was studied. It was determined that the most effective milling unit for synthesis of granite-based NB is ball mill, providing the maxal concentration of nano- and microsized particles and, therefore, the highest reactivity and binding characteristics.
\end{abstract}

\section{Introduction}

Nowadays, in Russia, the problem of energy saving, development of energy saving technologies as well as reducing in energy consumption when production process is relevant. Regulatory documents, accepted in last time, are oriented on the same problem in construction. It is important to note that Portland cement almost only is used for production of construction materials. However, due to high energy consumption and negative ecological effect when cement production there is requirement to develop new mineral binders with alternative mechanisms of consolidation.

At present time, synthesis of high-performance binders of new generation is followed by using of complex raw compositions. Production of these binders is possible by using high-tech only, and with science-based approaches. Consolidation mechanism of them is different from hydration. The most suitable ones are silicate and alumosilicate binders with polymerization-polycondensation consolidation mechanism - free-of-cement nanostructured binders (NB), where nanosized component plays the key role.

Production technology of NB is a «green» and it consists of «cold» synthesis in aqueous medium. The wide range of $\mathrm{SiO}_{2}$-bearing rocks can be used that allows adaption of this technology to different regions depending on deposit location.

By earlier studies [1-3] the principal opportunity of NB production was reported using $\mathrm{SiO}_{2}$ - and $\mathrm{SiO}_{2}-\mathrm{Al}_{2} \mathrm{O}_{3}$ bearing rocks of different genesis such as followings: quartz sand, sandstone, quartzite, perlite, zeolitized tuff.

\footnotetext{
* Corresponding author: kozhukhovanata@yandex.ru
} 
The basic subject of this study was to compare the mechanoactivation efficiency of different types of milling units when «cold» synthesis of NB using granite (acidic intrusive rock). Other subject was to choose the most energy saving milling unit from the point of view of dispersity of granite when NB synthesis.

At present, granite as a raw material is popular in different civil fields including construction.

On the other side, taking into account the economics of the country, the building materials market is in need of globally competitive and not expensive products. It can be produced using industrially-made raw materials from different areas, particularly, grinding residue of granite when granite aggregate production.

Nowadays, utilization of grinding residue of granite is one of the big problem for companies-manufacturers. Applying of old technology, the content of granite by-products is achieved up to $40 \%$ depending on fraction of granite aggregate and can't be reduced. So, effective using of it is quite relevant $[4,5]$.

Total volume of by-products from granite aggregate production in Russia is more than 19,7 million tons per a year [6].

The leaders of granite production $(\approx 57 \%$ ) are the followings: Republic of Karelia, Leningrad Oblast, Voronezh Region. The companies-producers offer, mainly, unwashed and non-fractioned granite residue with size of $0-5 \mathrm{~mm}$. It is not expensive and intensively materials used in road construction [7-9].

Adding of granite residue into cement concrete is limited by anisotropic morphology of grains and high concentration of fine-dispersed particles (18-25\%) according to [10].

In some companies the classification by fraction is realized applying a special equipment. But it is very energy-consuming.

Thus, the scientists in material science area are focused on more deep study of grinding residue from different rocks to extend of their application area.

It should be noted that, by now, granite was used as inert filler only (in different binders) and doesn't participate when structuring and consolidation processes [11, 12].

By scientific team from BSTU named after V.G. Shukhov (Russia) was determined, that during a wet mechanoactivation the granite transforms to reactive component with binding property [13].

The hypothesis of this study was the theory the aluminosilicate (natural or technogenic) raw materials after effective mechanoactivation could become a geopolymers without external alkali activation $[14,15]$.

Appearance of binding properties takes place as a result of alkali activation of aluminosilicate gel / geopolymerization according to J. Davidovitz [16].

Precursors for aluminosilicate gel synthesis was quartz (silicate component) and feldspar (aluminosilicate component) in granite. As a balancer of negative charge of $\mathrm{SiO}_{2}$ - and A12O3 - tetraheadra when geopolymerization were alkaline and alkaline-earth elements released from structure of feldspar and glist when mechanoactivation.

Normally, formation of globules of aluminosilicate gel leads to nanosized zeolitization that is responsible for strength characteristics. So, this binder can be called as nanostructured.

\section{Methods}

As an initial aluminosilicate raw material for binder synthesis the granite by-product from Poltavsky deposit (Ukraine) was used.

Chemical and mineral compositions of granite component was determined with XRFanalysis by ARL 9900 X-ray WorkStation (Termo Scientific) (Table 1); and XRD-analysis - by difractometer ARL X'tra using CuK 1,2. 
Table 1.Chemical composition of granite, $\%$

\begin{tabular}{|c|c|c|c|c|c|c|c|c|c|}
\hline $\mathbf{L O I}$ & $\mathbf{S i O}_{2}$ & $\mathrm{Al}_{2} \mathbf{O}_{3}$ & $\mathbf{F e}_{2} \mathbf{O}_{3}$ & $\mathbf{C a O}$ & $\mathbf{M g O}$ & $\mathbf{S O}_{3}$ & $\mathbf{K}_{2} \mathbf{O}$ & $\mathbf{N a}_{2} \mathbf{O}$ & $\Sigma$ \\
\hline 0.75 & 69.2 & 15.7 & 3.35 & 3.14 & 0.89 & 0.09 & 2.06 & 4.29 & 99.47 \\
\hline
\end{tabular}

Specific surface area was measured by SoftSorbi-II ver.1.0. machine using nitrogen as an adsorbing gaze.

Granulometry analysis of granite when its mechanoactivation was determined with laser particle analyzer Fritsch Analysette 22 Nano Tec plus.

Microstructure of the synthesized NB was studied with polarization microscope POLAM P12 and scanning electron microscope TESCAN MIRA 3 LMU.

\section{Results and Discussion}

According to results of XRD-analysis, mineral composition of granite component is the following (wt. \%) : quartz - 35.9; albite - 51.9; anortite - 3.9; amphibole - 3.3; biotite - 3.9. Granite component is a polymineral where minerals strongly differed from each other in microstructure and mechanic characteristics. Probably, intensity of their mechanoactivation is different as well.

To realize mechanoactivating process the following three type of milling units were applied: planetary mill MP4/0.5; vibrating mill IV; ball-mill RMSh-200 with $\mathrm{Al}_{2} \mathrm{O}_{3}$-inwall.

The binder was produced by mechanochemical synthesis in aqueous medium.

The key quality criterion for this binder is growth of concentration of amorphous aluminosilicate constituent. During the milling process the stage-by-stage monitoring of transformation in structure and chemical-mineral composition of the synthesized binding system took place.

Mechanoactivation was realized to achieve specific surface area $\approx 7000 \mathrm{~cm} 2 / \mathrm{g}$ for each milling unit.

Mechanoactivation in planetary mill allows realization two processes simultaneously: activation (increasing of reactivity) and mechanochemical synthesis (formation of new component). Application of planetary mill provides significant over-loading leading the efficiency growth of milling process.

Data of granulometry analysis for granite component after milling in different mills is shown in Fig. 1.

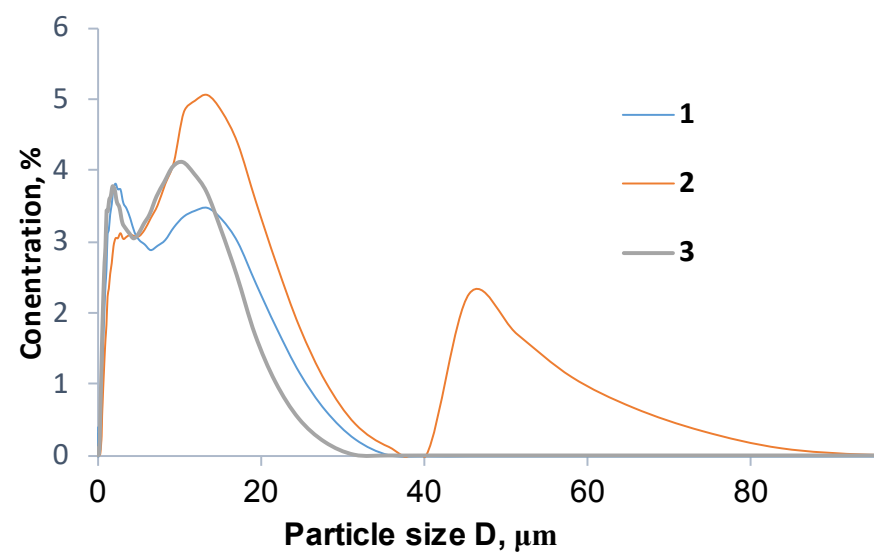

Fig. 1. Granulometry for granite component after milling in: 1 - ball mill; 2 - planetary mill; 3 vibrating mill 
Mechanoactivation in vibrating mill IV-1 allows homogeneous milling of polymineral raw materials up to fine-disperse state. With this mill milling process was realized by simultaneous combination of two effects: vibration and abrasion.

Mechanoactivation in ball mill RMSh-200 also realized two effects: shock and abrasion.

When wet mechanoactivation, volumetric content of water is reduced but shearing force and temperature (from $20{ }^{\circ} \mathrm{C}$ to $110{ }^{\circ} \mathrm{C}$ ) of system grows. This initiates a growth of mechanoactivation energy and flow ability as well as reducing in viscosity of binder that allows mechanoactivation at high concentration of solid phase.

Under above conditions the binding system was synthesized with specific surface area of $7300 \mathrm{~cm} 2 / \mathrm{g}$, and concentration of particles with size up to $5 \mu \mathrm{m}-48 \%$

Analyzing granulometry curves (Fig. 1) it can be concluded that the most effective mechanoactivation for granite takes place in ball and planetary mills (concentration of particles in size range of $0.1-0.01 \mu \mathrm{m}$ is 12 and $4 \%$, respectively. But, content of particles with size of $1-10 \mu \mathrm{m}$ after vibrating and ball mills is higher vs. planetary mill by 30 and 50 $\%$, respectively. Modal particle diameters of binder, synthesized in ball, planetary and vibrating mills were $2.03,12.12$ and 9.98 , respectively.

\section{Summary}

Thus, according to the results obtained, the most effective milling unit for synthesis of granite-based NB is ball mill, providing with the maximal concentration of nano- and microsized particles and, therefore, the highest reactivity and binding characteristics.

The most energy saving granite component from the point of view of grindability when mechanoactivation is granite residue with maximal content of quartz and minimal content of biotite.

This work was realized in the framework of the Program of flagship university development on the base of the Belgorod State Technological University named after V G Shukhov, using equipment of High Technology Center at BSTU named after V G Shukhov.

\section{References}

1. V.A. Doroganov, Yu.E. Pivinskii, A.V. Cherevatova, Refractories and Industrial Ceramics, 45(3), 172-176 (2004).

2. V.A. Doroganov, Yu. E. Pivinskii, Refractories and Industrial Ceramics, 46(2), 120$126(2005)$.

3. Yu.E. Pivinskii, Refractories and Industrial Ceramics, 44(3), 152-160 (2003).

4. N.I. Kozhuhova, I.V. Zhernovskiy, M.S. Osadchaya, V.V. Strokova, R.V. Tchizhov, International Journal of Applied Engineering Research (IJAER), 9 16945-16955 (2014).

5. N.I. Kozhuhova, I.V. Zhernovskiy, M.S. Osadchaya, V.V. Strokova, R.V.Tchizhov Research Journal of Applied Science, 9(12), 1034-1039 (2014).

6. http://stroy.prompages.ru/article.php?id_it=1344

7. Dawei Wang, Xianhua Chen, Xiaoguang Xie, Helge Stanjek, Bernhard Steinauer, Construction and Building Materials, 89, 25-35 (2015).

8. A.I. Trautvain, Construction Materials and Products, 2(1), 17-23 (2019).

9. V.V. Yadyikina, A.M. Gridchin, A.I. Trautvain, Yu.P. Chistyakov, Bulletin of BSTU named after V.G. Shukhov, 6, 149-153 (2015). 
10. V.A. Artamonov, V.V. Vorobyev, V.S. Svitov, Stroitel'nye materialy, 6, 28-29 (2003).

11. N.I. Alfimova, V.S. Lesovik, A.V. Savin, E.E. Shadsky, Proceedings of Irkutsk State Technical University, 5(88), 95-99 (2014).

12. Sarbjeet Singh, Ravindra Nagar, Vinay Agrawal, Journal of Cleaner Production, 126, 74-87 (2016).

13. A.V. Cherevatova, I.V. Zhernovsky, V.V. Strokova, Mineral nanostructured binders. Nature, technology and application prospects (LAM LAMBERT Academic Publishing GmbH \& Co. KG. Saarbrucken, 2011)

14. N.I. Kozhukhova, V.V. Strokova, M.I. Kozhukhova, I.V. Zhernovsky, Construction Materials and Products, 1(4), 38-43 (2018).

15. R.V. Chizhov, N.I. Kozhukhova, V.V. Strokova, I.V. Zhernovsky, Bulletin of BSTU named after V.G. Shukhov, 4, 6-10 (2016).

16. Joseph Davidovits, Luis Huaman, Ralph Davidovits, Materials Letters, 235, 120-124 (2019). 